\title{
Strong convergence theorems for fixed point problems, variational inequality problems, and equilibrium problems
}

\author{
Zhangsong Yao', Yeong-Cheng Liou ${ }^{2,3 *}$, Li-Jun Zhu' ${ }^{4}$ Ching-Hua Lo and Chen-Chang Wu²
}

"Correspondence:
simplex_liou@hotmail.com
2Department of Information
Management, Cheng Shiu
University, Kaohsiung, 833, Taiwan
${ }^{3}$ Center for General Education,
Kaohsiung Medical University,
Kaohsiung, 807, Taiwan
Full list of author information is
available at the end of the article

available at the end of the article

\begin{abstract}
In this paper, we first introduce an iterative algorithm for finding a common element of the set of fixed points of a nonexpansive mapping, the set of solutions of an equilibrium problem, and the solution set of the variational inequality problem for a monotone mapping in a real Hilbert space. Furthermore, we prove that the proposed iterative algorithm converges strongly to a common element of the above three sets under some mild conditions.
\end{abstract}

MSC: 49J30; 47H09; 47H2O

Keywords: nonexpansive mapping; equilibrium problem; fixed point; variational inequality

\section{Introduction}

Equilibrium problems theory provides us a natural, novel and unified framework to study a wide class of problems arising in economics, finance, transportation, network and structural analysis, elasticity and optimization. The ideas and techniques of this theory are being used in a variety of diverse areas and proved to be productive and innovative. It has been shown by Blum and Oettli [1] and Noor and Oettli [2] that variational inequalities and mathematical programming problems can be viewed as special realization of the abstract equilibrium problems. Equilibrium problems have numerous applications, including but not limited to problems in economics, game theory, finance, traffic analysis, circuit network analysis, and mechanics.

There are a substantial number of numerical methods including projection technique and its variant forms, Wiener-Hopf equations, the auxiliary principle technique, and resolvent equations methods for solving variational inequalities. However, it is well known that projection, Wiener-Hopf equations, and proximal and resolvent equations techniques cannot be extended and generalized to suggest and analyze similar iterative methods for solving equilibrium problems. This fact has motivated us to use the auxiliary principle technique for solving the equilibrium problems. MA Noor and KI Noor [3] and MA Noor [4] used this technique to suggest implicit and explicit iterative methods for solving equilibrium problems. Related to this problem, much attention has been given to finding the fixed point of nonexpansive and contraction mappings. It is natural to combine these two 
different problems and study the problem of finding the equilibrium problem coupled with fixed point problem. In this direction, Combettes and Hirstoaga [5] introduced an iterative scheme for finding the best approximation to the initial data of the equilibrium problem and proved a strong convergence result. See also [6-16] and the references therein for more details. It is our purpose in this paper that we introduce an iterative algorithm for finding a common element of the set of fixed points of a nonexpansive mapping, the set of solutions of an equilibrium problem, and the solution set of the variational inequality problem. We show the proposed algorithm has strong convergence.

Let $H$ be a real Hilbert space with inner product $\langle\cdot, \cdot\rangle$ and norm $\|\cdot\|$, and let $C$ be a closed convex subset of $H$. A mapping $A$ of $C$ into $H$ is called monotone if

$$
\langle A u-A v, u-v\rangle \geq 0, \quad \forall u, v \in C .
$$

$A: C \rightarrow H$ is called $\alpha$-inverse-strongly-monotone if there exists a positive real number $\alpha$ such that

$$
\langle A u-A v, u-v\rangle \geq \alpha\|A u-A v\|^{2}, \quad \forall u, v \in C
$$

(see Browder and Petryshyn [17]; Liu and Nashed [18]). It is obvious that any $\alpha$-inversestrongly monotone mapping $A$ is monotone and $\frac{1}{\alpha}$-Lipschitz continuous. A mapping $S$ : $C \rightarrow H$ is said to be nonexpansive if

$$
\|S x-S y\| \leq\|x-y\|, \quad \forall x, y \in C .
$$

We denote by $\operatorname{Fix}(S)$ the set of fixed points of $S$.

Recall that the classical variational inequality, denoted by $\operatorname{VI}(A, C)$, is to find $x^{*} \in C$ such that

$$
\left\langle A x^{*}, v-x^{*}\right\rangle \geq 0 \quad \text { for all } v \in C \text {. }
$$

The variational inequalities have been widely studied in the literature; see, e.g., [19-25] and the references therein.

For finding an element of $\operatorname{Fix}(S) \cap \operatorname{VI}(A, C)$ under the assumption that a mapping $A$ of $C$ into $H$ is $\alpha$-inverse-strongly-monotone, Takahashi and Toyoda [26] introduced the following iterative scheme:

$$
x_{n+1}=\alpha_{n} x_{n}+\left(1-\alpha_{n}\right) S P_{C}\left(x_{n}-\lambda_{n} A x_{n}\right)
$$

for every $n=0,1,2, \ldots$, where $P_{C}$ is the metric projection of $H$ onto $C, x_{0}=x \in C,\left\{\alpha_{n}\right\}$ is a sequence in $(0,1)$, and $\left\{\lambda_{n}\right\}$ is a sequence in $(0,2 \alpha)$. On the other hand, for solving the variational inequality problem in the finite-dimensional Euclidean space $R^{n}$, Korpelevich [27] introduced the following so-called extragradient method:

$$
\left\{\begin{array}{l}
x_{0}=x \in C, \\
y_{n}=P_{C}\left(x_{n}-\lambda A x_{n}\right), \\
x_{n+1}=P_{C}\left(x_{n}-\lambda A y_{n}\right)
\end{array}\right.
$$


for every $n=0,1,2, \ldots$, where $\lambda \in(0,1 / k)$. Recently, Nadezhkina and Takahashi [6] introduced another extragradient method for finding a common element of the set of fixed points of a nonexpansive mapping and the set of solutions of a variational inequality problem. They obtained the following result.

Theorem 1.1 ([6]) Let C be a nonempty closed convex subset of a real Hilbert space H. Let $A: C \rightarrow H$ be a monotone, $k$-Lipschitz continuous mapping, and let $S: C \rightarrow C$ be a nonexpansive mapping such that $\operatorname{Fix}(S) \cap \operatorname{VI}(A, C) \neq \emptyset$. Let the sequences $\left\{x_{n}\right\},\left\{y_{n}\right\}$ be generated by

$$
\left\{\begin{array}{l}
x_{0}=x \in H \\
y_{n}=P_{C}\left(x_{n}-\lambda_{n} A x_{n}\right), \\
x_{n+1}=\alpha_{n} x_{n}+\left(1-\alpha_{n}\right) S P_{C}\left(x_{n}-\lambda_{n} A y_{n}\right), \quad \forall n \geq 0
\end{array}\right.
$$

where $\left\{\lambda_{n}\right\} \subset[a, b]$ for some $a, b \in(0,1 / k)$ and $\left\{\alpha_{n}\right\} \subset[c, d]$ for some $c, d \in(0,1)$. Then the sequences $\left\{x_{n}\right\},\left\{y_{n}\right\}$ generated by (1.1) converge weakly to the same point $P_{\mathrm{Fix}(S) \cap \mathrm{VI}(A, C)}\left(x_{0}\right)$.

The iterative scheme (1.1) in Theorem 1.1 has only weak convergence. In order to obtain strong convergence theorem, very recently, Zeng and Yao [11] further introduced a new extragradient method for finding a common element of the set of fixed points of a nonexpansive mapping and the set of solutions of a variational inequality problem. They proved the following interesting result.

Theorem 1.2 ([11]) Let $C$ be a nonempty closed convex subset of a real Hilbert space H. Let $A: C \rightarrow H$ be a monotone, $k$-Lipschitz continuous mapping, and let $S: C \rightarrow C$ be a nonexpansive mapping such that $\operatorname{Fix}(S) \cap \operatorname{VI}(A, C) \neq \emptyset$. Let the sequences $\left\{x_{n}\right\},\left\{y_{n}\right\}$ be generated by

$$
\left\{\begin{array}{l}
x_{0}=x \in H, \\
y_{n}=P_{C}\left(x_{n}-\lambda_{n} A x_{n}\right), \\
x_{n+1}=\alpha_{n} x_{0}+\left(1-\alpha_{n}\right) S P_{C}\left(x_{n}-\lambda_{n} A y_{n}\right), \quad \forall n \geq 0,
\end{array}\right.
$$

where $\left\{\lambda_{n}\right\}$ and $\left\{\alpha_{n}\right\}$ satisfy the conditions:

(a) $\left\{\lambda_{n} k\right\} \subset(0,1-\delta)$ for some $\delta \in(0,1)$;

(b) $\left\{\alpha_{n}\right\} \subset(0,1), \sum_{n=0}^{\infty} \alpha_{n}=\infty, \lim _{n \rightarrow \infty} \alpha_{n}=0$.

Then the sequences $\left\{x_{n}\right\}$ and $\left\{y_{n}\right\}$ converge strongly to the same point $P_{\mathrm{Fix}(S) \cap \mathrm{VI}(A, C)}\left(x_{0}\right)$ provided

$$
\lim _{n \rightarrow \infty}\left\|x_{n+1}-x_{n}\right\|=0
$$

Now we concern ourselves with the following equilibrium problem: Find $x \in C$ such that

$$
\mathrm{EP}: F(x, y) \geq 0 \text { for all } y \in C,
$$

where $F$ is an equilibrium bifunction of $C \times C$ into $\mathbf{R}$. The set of solutions of (1.3) is denoted by $\operatorname{EP}(F)$. Given a mapping $T: C \rightarrow H$, let $F(x, y)=\langle T x, y-x\rangle$ for all $x, y \in C$. Then $z \in$ $\operatorname{EP}(F)$ if and only if $\langle T z, y-z\rangle \geq 0$ for all $y \in C$. 
For solving equilibrium problem (1.1), Takahashi and Takahashi [9] introduced an iterative scheme by the viscosity approximation method for finding a common element of the set of solutions of an equilibrium problem and the set of fixed points of a nonexpansive mapping in a Hilbert space. Let $S: C \rightarrow H$ be a nonexpansive mapping. Starting with arbitrary initial $x_{1} \in H$, define sequences $\left\{x_{n}\right\}$ and $\left\{u_{n}\right\}$ recursively by

$$
\left\{\begin{array}{l}
F\left(u_{n}, y\right)+\frac{1}{r_{n}}\left\langle y-u_{n}, u_{n}-x_{n}\right\rangle \geq 0, \quad \forall y \in C, \\
x_{n+1}=\alpha_{n} f\left(x_{n}\right)+\left(1-\alpha_{n}\right) S u_{n}, \quad \forall n \geq 0 .
\end{array}\right.
$$

They proved that the sequences $\left\{x_{n}\right\}$ and $\left\{u_{n}\right\}$ converge strongly to $z \in \operatorname{Fix}(S) \cap \operatorname{EP}(F)$ with the following restrictions on the algorithm parameters $\left\{\alpha_{n}\right\}$ and $\left\{r_{n}\right\}$ :

(i) $\lim _{n \rightarrow \infty} \alpha_{n}=0$ and $\sum_{n=0}^{\infty} \alpha_{n}=\infty$;

(ii) $\liminf _{n \rightarrow \infty} r_{n}>0$;

(iii) (A1): $\sum_{n=0}^{\infty}\left|\alpha_{n+1}-\alpha_{n}\right|<\infty$; and (R1): $\sum_{n=0}^{\infty}\left|r_{n+1}-r_{n}\right|<\infty$.

Motivated and inspired by the work of Zeng and Yao [11], Takahashi and Takahashi [9], in this paper, we first introduce an iterative algorithm for finding a common element of the set of fixed points of a nonexpansive mapping, the set of solutions of an equilibrium problem, and the solution set of the variational inequality problem for a monotone mapping in a real Hilbert space. Furthermore, we prove that the proposed iterative algorithm converges strongly to a common element of the above three sets under some mild conditions. Our result includes the result of Zeng and Yao [11] as a special case.

\section{Preliminaries}

Let $C$ be a nonempty closed convex subset of a real Hilbert space $H$. It is well known that, for any $u \in H$, there exists a unique $y_{0} \in C$ such that

$$
\left\|u-y_{0}\right\|=\inf \{\|u-y\|: y \in C\} .
$$

We denote $y_{0}$ by $P_{C} u$, where $P_{C}$ is called the metric projection of $H$ onto $C$. The metric projection $P_{C}$ of $H$ onto $C$ is characterized by the following properties:

(i) $\left\|P_{C} x-P_{C} y\right\| \leq\|x-y\|$ for all $x, y \in H$,

(ii) $\left\langle x-y, P_{C} x-P_{C} y\right\rangle \geq\left\|P_{C} x-P_{C} y\right\|^{2}$ for every $x, y \in H$,

(iii) $\left\langle x-P_{C} x, y-P_{C} x\right\rangle \leq 0$ for all $x \in H, y \in C$,

(iv) $\|x-y\|^{2} \geq\left\|x-P_{C} x\right\|^{2}+\left\|y-P_{C} x\right\|^{2}$ for all $x \in H, y \in C$.

Let $A$ be a monotone mapping of $C$ into $H$. In the context of the variational inequality problem, it is easy to see from (iv) that

$$
u \in \operatorname{VI}(A, C) \Leftrightarrow u=P_{C}(u-\lambda A u), \quad \forall \lambda>0 .
$$

A set-valued mapping $B: H \rightarrow 2^{H}$ is called monotone if, for all $x, y \in H, f \in B x$ and $g \in B y$ imply $\langle x-y, f-g\rangle \geq 0$. A monotone mapping $B: H \rightarrow 2^{H}$ is maximal if its graph $G(B)$ is not properly contained in the graph of any other monotone mapping. It is well known that a monotone mapping $B$ is maximal if and only if, for $(x, f) \in H \times H,\langle x-y, f-g\rangle \geq 0$ for every $(y, g) \in G(B)$ implies $f \in B x$. Let $A$ be a monotone mapping of $C$ into $H$, and let $N_{C} v$ be the normal cone to $C$ at $v \in C$; i.e.,

$$
N_{C} v=\{w \in H:\langle v-u, w\rangle \geq 0, \forall u \in C\} .
$$


Define

$$
B v= \begin{cases}A v+N_{C} v, & \text { if } v \in C, \\ \emptyset, & \text { if } v \notin C .\end{cases}
$$

Then $B$ is maximal monotone and $0 \in B v$ if and only if $v \in \operatorname{VI}(A, C)$.

In this paper, for solving the equilibrium problems for a bifunction $F: C \times C \rightarrow \mathbf{R}$, we assume that $F$ satisfies the following conditions:

(H1) $F(x, x)=0$ for all $x \in C$;

(H2) $F$ is monotone, i.e., $F(x, y)+F(y, x) \leq 0$ for all $x, y \in C$;

(H3) for each $x, y, z \in C, \lim _{t \downarrow 0} F(t z+(1-t) x, y) \leq F(x, y)$;

(H4) for each $x \in C, y \mapsto F(x, y)$ is convex and lower semi-continuous.

In the sequel, we shall need the following lemmas for proving our main result.

Lemma 2.1 ([5]) Let $C$ be a nonempty closed convex subset of $H$, and let $F$ be a bifunction of $C \times C$ into $\mathbf{R}$ satisfying conditions (H1)-(H4). Let $r>0$ and $x \in C$. Then there exists $y \in C$ such that

$$
F(y, z)+\frac{1}{r}\langle z-y, y-x\rangle \geq 0 \quad \text { for all } z \in C .
$$

Lemma 2.2 ([5]) Assume that $F$ satisfies the same assumptions as in Lemma 2.1. For $r>0$ and $x \in C$, define a mapping $T_{r}: H \rightarrow C$ as follows:

$$
T_{r}(x)=\left\{y \in C: F(y, z)+\frac{1}{r}\langle z-y, y-x\rangle \geq 0, \forall z \in C\right\}
$$

for all $y \in H$. Then the following hold:

(1) $T_{r}$ is single-valued;

(2) $T_{r}$ is firmly nonexpansive, i.e., for any $x, y \in H$,

$$
\left\|T_{r} x-T_{r} y\right\|^{2} \leq\left\langle T_{r} x-T_{r} y, x-y\right\rangle ;
$$

(3) $\operatorname{Fix}\left(T_{r}\right)=\operatorname{EP}(F)$;

(4) $\mathrm{EP}(F)$ is closed and convex.

Lemma 2.3 ([28]) Assume $\left\{a_{n}\right\}$ is a sequence of nonnegative real numbers such that

$$
a_{n+1} \leq\left(1-\gamma_{n}\right) a_{n}+\delta_{n}
$$

where $\left\{\gamma_{n}\right\}$ is a sequence in $(0,1)$ and $\left\{\delta_{n}\right\}$ is a sequence such that

(1) $\sum_{n=1}^{\infty} \gamma_{n}=\infty$;

(2) $\lim \sup _{n \rightarrow \infty} \delta_{n} / \gamma_{n} \leq 0$ or $\sum_{n=1}^{\infty}\left|\delta_{n}\right|<\infty$.

Then $\lim _{n \rightarrow \infty} a_{n}=0$.

\section{Main results}

In this section, we first introduce the following iterative algorithm. 
Algorithm 3.1 Let $C$ be a nonempty closed convex subset of a real Hilbert space $H$. Let $F$ be a bifunction from $C \times C \rightarrow \mathbf{R}$. Let $A: C \rightarrow H$ be a nonlinear mapping, and let $S: C \rightarrow C$ a mapping. For fixed $u \in C$ and given $x_{0} \in C$ arbitrarily, suppose the sequences $\left\{x_{n}\right\},\left\{y_{n}\right\}$, and $\left\{u_{n}\right\}$ are generated iteratively by

$$
\left\{\begin{array}{l}
F\left(u_{n}, y\right)+\frac{1}{r_{n}}\left\langle y-u_{n}, u_{n}-x_{n}\right\rangle \geq 0, \quad \forall y \in C, \\
y_{n}=P_{C}\left(u_{n}-\lambda_{n} A u_{n}\right) \\
x_{n+1}=\alpha_{n} u+\beta_{n} x_{n}+\left(1-\alpha_{n}-\beta_{n}\right) S P_{C}\left(u_{n}-\lambda_{n} A y_{n}\right),
\end{array}\right.
$$

where $\left\{\alpha_{n}\right\}$ and $\left\{\beta_{n}\right\}$ are two sequences in $(0,1)$ and $\left\{\lambda_{n}\right\}$ and $\left\{r_{n}\right\}$ are two sequence in $(0, \infty)$.

Next we prove the strong convergence of Algorithm 3.1.

Theorem 3.2 Let $C$ be a nonempty closed convex subset of a real Hilbert space H. Let $F$ be a bifunction from $\mathrm{C} \times \mathrm{C} \rightarrow \mathbf{R}$ satisfying $(\mathrm{H} 1)-(\mathrm{H} 4)$. Let $A$ be a monotone and $k$-Lipschitz continuous mapping of $C$ into $H$, and let $S$ be a nonexpansive mapping of $C$ into itself such that $\operatorname{Fix}(S) \cap \operatorname{VI}(A, C) \cap \operatorname{EP}(F) \neq \emptyset$. Assume that:

(a) $\left\{\lambda_{n} k\right\} \subset(0,1-\delta)$ for some $\delta \in(0,1)$;

(b) $\lim _{n \rightarrow \infty} \alpha_{n}=0$ and $\sum_{n=0}^{\infty} \alpha_{n}=\infty$;

(c) $\lim \sup _{n \rightarrow \infty} \beta_{n}<1$.

Then the sequences $\left\{x_{n}\right\},\left\{y_{n}\right\}$, and $\left\{u_{n}\right\}$ generated by (3.1) converge strongly to $P_{\mathrm{Fix}(S) \cap \mathrm{VI}(A, C) \cap \mathrm{EP}(F)}(u)$ if and only if $\lim _{n \rightarrow \infty}\left\|x_{n+1}-x_{n}\right\|=0$.

Proof The necessity is obvious. Next we prove the sufficiency.

Let $x^{*} \in \operatorname{Fix}(S) \cap \operatorname{VI}(A, C) \cap \operatorname{EP}(F)$, and let $\left\{T_{r_{n}}\right\}$ be a sequence of mappings defined as in Lemma 2.2. Then we have $x^{*}=P_{C}\left(x^{*}-\lambda_{n} A x^{*}\right)=T_{r_{n}} x^{*}$.

Set $z_{n}=P_{C}\left(u_{n}-\lambda_{n} A y_{n}\right)$ for all $n \geq 0$. From the property (iv) of $P_{C}$, we have

$$
\begin{aligned}
\left\|z_{n}-x^{*}\right\|^{2} \leq & \left\|u_{n}-\lambda_{n} A y_{n}-x^{*}\right\|^{2}-\left\|u_{n}-\lambda_{n} A y_{n}-z_{n}\right\|^{2} \\
= & \left\|u_{n}-x^{*}\right\|^{2}-2 \lambda_{n}\left\langle A y_{n}, u_{n}-x^{*}\right\rangle+\lambda_{n}^{2}\left\|A y_{n}\right\|^{2} \\
& -\left\|u_{n}-z_{n}\right\|^{2}+2 \lambda_{n}\left\langle A y_{n}, u_{n}-z_{n}\right\rangle-\lambda_{n}^{2}\left\|A y_{n}\right\|^{2} \\
= & \left\|u_{n}-x^{*}\right\|^{2}-\left\|u_{n}-z_{n}\right\|^{2}+2 \lambda_{n}\left|A y_{n}, x^{*}-z_{n}\right\rangle \\
= & \left\|u_{n}-x^{*}\right\|^{2}-\left\|u_{n}-z_{n}\right\|^{2}+2 \lambda_{n}\left\langle A y_{n}-A x^{*}, x^{*}-y_{n}\right\rangle \\
& +2 \lambda_{n}\left\langle A x^{*}, x^{*}-y_{n}\right\rangle+2 \lambda_{n}\left\langle A y_{n}, y_{n}-z_{n}\right\rangle .
\end{aligned}
$$

Using the fact that $A$ is monotonic and $x^{*}$ is a solution of the variational inequality problem $\mathrm{VI}(A, C)$, we have

$$
\left\langle A y_{n}-A x^{*}, x^{*}-y_{n}\right\rangle \leq 0 \text { and }\left\langle A x^{*}, x^{*}-y_{n}\right\rangle \leq 0 .
$$

It follows from (3.2) and (3.3) that

$$
\begin{aligned}
\left\|z_{n}-x^{*}\right\|^{2} & \leq\left\|u_{n}-x^{*}\right\|^{2}-\left\|u_{n}-z_{n}\right\|^{2}+2 \lambda_{n}\left\langle A y_{n}, y_{n}-z_{n}\right\rangle \\
& =\left\|u_{n}-x^{*}\right\|^{2}-\left\|u_{n}-y_{n}\right\|^{2}-2\left\langle u_{n}-y_{n}, y_{n}-z_{n}\right\rangle
\end{aligned}
$$




$$
\begin{aligned}
& -\left\|y_{n}-z_{n}\right\|^{2}+2 \lambda_{n}\left\langle A y_{n}, y_{n}-z_{n}\right\rangle \\
= & \left\|u_{n}-x^{*}\right\|^{2}-\left\|u_{n}-y_{n}\right\|^{2}+2\left\langle u_{n}-\lambda_{n} A y_{n}-y_{n}, z_{n}-y_{n}\right\rangle \\
& -\left\|y_{n}-z_{n}\right\|^{2} .
\end{aligned}
$$

By using the property (iii) of $P_{C}$, we have $\left\langle u_{n}-\lambda_{n} A u_{n}-y_{n}, z_{n}-y_{n}\right\rangle \leq 0$. Therefore, we get

$$
\begin{aligned}
\left\langle u_{n}-\lambda_{n} A y_{n}-y_{n}, z_{n}-y_{n}\right\rangle= & \left\langle u_{n}-\lambda_{n} A u_{n}-y_{n}, z_{n}-y_{n}\right\rangle \\
& +\lambda_{n}\left\langle A u_{n}-A y_{n}, z_{n}-y_{n}\right\rangle \\
\leq & \lambda_{n}\left\langle A u_{n}-A y_{n}, z_{n}-y_{n}\right\rangle \\
\leq & \lambda_{n}\left\|A u_{n}-A y_{n}\right\|\left\|z_{n}-y_{n}\right\| \\
\leq & \lambda_{n} k\left\|u_{n}-y_{n}\right\|\left\|z_{n}-y_{n}\right\| .
\end{aligned}
$$

Combining (3.4) and (3.5), we obtain

$$
\begin{aligned}
\left\|z_{n}-x^{*}\right\|^{2} \leq & \left\|u_{n}-x^{*}\right\|^{2}-\left\|u_{n}-y_{n}\right\|^{2}-\left\|y_{n}-z_{n}\right\|^{2} \\
& +2 \lambda_{n} k\left\|u_{n}-y_{n}\right\|\left\|z_{n}-y_{n}\right\| \\
\leq & \left\|u_{n}-x^{*}\right\|^{2}-\left\|u_{n}-y_{n}\right\|^{2}-\left\|y_{n}-z_{n}\right\|^{2} \\
& +\lambda_{n}^{2} k^{2}\left\|u_{n}-y_{n}\right\|^{2}+\left\|z_{n}-y_{n}\right\|^{2} \\
= & \left\|u_{n}-x^{*}\right\|^{2}+\left(\lambda_{n}^{2} k^{2}-1\right)\left\|u_{n}-y_{n}\right\|^{2} \\
\leq & \left\|u_{n}-x^{*}\right\|^{2} \\
= & \left\|T_{r_{n}} x_{n}-T_{r_{n}} x^{*}\right\|^{2} \\
\leq & \left\|x_{n}-x^{*}\right\|^{2} .
\end{aligned}
$$

From (3.1), we deduce that

$$
\begin{aligned}
\left\|x_{n+1}-x^{*}\right\| & =\left\|\alpha_{n}\left(u-x^{*}\right)+\beta_{n}\left(x_{n}-x^{*}\right)+\left(1-\alpha_{n}-\beta_{n}\right)\left(S z_{n}-x^{*}\right)\right\| \\
& \leq \alpha_{n}\left\|u-x^{*}\right\|+\beta_{n}\left\|x_{n}-x^{*}\right\|+\left(1-\alpha_{n}-\beta_{n}\right)\left\|z_{n}-x^{*}\right\| \\
& \leq \alpha_{n}\left\|u-x^{*}\right\|+\left(1-\alpha_{n}\right)\left\|x_{n}-x^{*}\right\| .
\end{aligned}
$$

It follows from (3.7) and induction that

$$
\left\|x_{n}-p\right\| \leq \max \left\{\left\|u-x^{*}\right\|,\left\|x_{0}-x^{*}\right\|\right\}, \quad n \geq 0 .
$$

Hence $\left\{x_{n}\right\}$ is bounded. It is clear that $\left\{y_{n}\right\},\left\{u_{n}\right\}$, and $\left\{z_{n}\right\}$ are all bounded.

Next, we show $\left\|y_{n}-S y_{n}\right\| \rightarrow 0$. From $x_{n+1}=\alpha_{n} u+\beta_{n} x_{n}+\left(1-\alpha_{n}-\beta_{n}\right) S z_{n}$, we have

$$
\begin{aligned}
\left\|x_{n}-S z_{n}\right\| \leq & \left\|x_{n}-x_{n+1}\right\|+\left\|x_{n+1}-S z_{n}\right\| \\
\leq & \left\|x_{n}-x_{n+1}\right\|+\alpha_{n}\left\|u-S z_{n}\right\| \\
& +\beta_{n}\left\|x_{n}-S z_{n}\right\|,
\end{aligned}
$$


that is,

$$
\left\|x_{n}-S z_{n}\right\| \leq \frac{1}{1-\beta_{n}}\left\|x_{n}-x_{n+1}\right\|+\frac{\alpha_{n}}{1-\beta_{n}}\left\|u-S z_{n}\right\| .
$$

This together with $\left\|x_{n+1}-x_{n}\right\| \rightarrow 0$ and $\alpha_{n} \rightarrow 0$ implies that

$$
\lim _{n \rightarrow \infty}\left\|x_{n}-S z_{n}\right\|=0
$$

Since $T_{r_{n}}$ is firmly nonexpansive, we have

$$
\begin{aligned}
\left\|u_{n}-x^{*}\right\|^{2} & =\left\|T_{r_{n}} x_{n}-T_{r_{n}} x^{*}\right\|^{2} \\
& \leq\left\langle T_{r_{n}} x_{n}-T_{r_{n}} x^{*}, x_{n}-x^{*}\right\rangle \\
& =\left\langle u_{n}-x^{*}, x_{n}-x^{*}\right\rangle \\
& =\frac{1}{2}\left(\left\|u_{n}-x^{*}\right\|^{2}+\left\|x_{n}-x^{*}\right\|^{2}-\left\|x_{n}-u_{n}\right\|^{2}\right)
\end{aligned}
$$

and hence

$$
\left\|u_{n}-x^{*}\right\|^{2} \leq\left\|x_{n}-x^{*}\right\|^{2}-\left\|x_{n}-u_{n}\right\|^{2} .
$$

By (3.1), we have

$$
\begin{aligned}
\left\|x_{n+1}-x^{*}\right\|^{2} & =\left\|\alpha_{n}\left(u-x^{*}\right)+\beta_{n}\left(x_{n}-x^{*}\right)+\left(1-\alpha_{n}-\beta_{n}\right)\left(S z_{n}-x^{*}\right)\right\|^{2} \\
& \leq \alpha_{n}\left\|u-x^{*}\right\|^{2}+\beta_{n}\left\|x_{n}-x^{*}\right\|^{2}+\left(1-\alpha_{n}-\beta_{n}\right)\left\|S z_{n}-x^{*}\right\|^{2} \\
& \leq \alpha_{n}\left\|u-x^{*}\right\|^{2}+\beta_{n}\left\|x_{n}-x^{*}\right\|^{2}+\left(1-\alpha_{n}-\beta_{n}\right)\left\|z_{n}-x^{*}\right\|^{2} .
\end{aligned}
$$

From (3.6) and (3.10), we have

$$
\begin{aligned}
\left\|x_{n+1}-x^{*}\right\|^{2} \leq & \alpha_{n}\left\|u-x^{*}\right\|^{2}+\beta_{n}\left\|x_{n}-x^{*}\right\|^{2}+\left(1-\alpha_{n}-\beta_{n}\right)\left[\left\|u_{n}-x^{*}\right\|^{2}\right. \\
& \left.+\left(\lambda_{n}^{2} k^{2}-1\right)\left\|u_{n}-y_{n}\right\|^{2}\right] \\
\leq & \alpha_{n}\left\|u-x^{*}\right\|^{2}+\beta_{n}\left\|x_{n}-x^{*}\right\|^{2}+\left(1-\alpha_{n}-\beta_{n}\right)\left[\left\|x_{n}-x^{*}\right\|^{2}\right. \\
& \left.+\left(\lambda_{n}^{2} k^{2}-1\right)\left\|u_{n}-y_{n}\right\|^{2}\right] \\
\leq & \alpha_{n}\left\|u-x^{*}\right\|^{2}+\left\|x_{n}-x^{*}\right\|^{2}+\left(1-\alpha_{n}-\beta_{n}\right) \\
& \times\left(\lambda_{n}^{2} k^{2}-1\right)\left\|u_{n}-y_{n}\right\|^{2} .
\end{aligned}
$$

Then we derive

$$
\begin{aligned}
& \left(1-\alpha_{n}-\beta_{n}\right)\left(1-\lambda_{n}^{2} k^{2}\right)\left\|u_{n}-y_{n}\right\|^{2} \\
& \quad \leq\left\|x_{n}-x^{*}\right\|^{2}-\left\|x_{n+1}-p\right\|^{2}+\alpha_{n}\left\|u-x^{*}\right\|^{2} \\
& \quad \leq\left(\left\|x_{n}-x^{*}\right\|+\left\|x_{n+1}-x^{*}\right\|\right) \times\left\|x_{n+1}-x_{n}\right\|+\alpha_{n}\left\|u-x^{*}\right\|^{2} .
\end{aligned}
$$


It is clear that $\liminf _{n \rightarrow \infty}\left(1-\alpha_{n}-\beta_{n}\right)\left(1-\lambda_{n}^{2} k^{2}\right)>0$. So, from (3.11), we have

$$
\lim _{n \rightarrow \infty}\left\|u_{n}-y_{n}\right\|=0
$$

From (3.6), (3.9), and (3.10), we have

$$
\begin{aligned}
\left\|x_{n+1}-x^{*}\right\|^{2} \leq & \alpha_{n}\left\|u-x^{*}\right\|^{2}+\beta_{n}\left\|x_{n}-x^{*}\right\|^{2}+\left(1-\alpha_{n}-\beta_{n}\right)\left\|z_{n}-x^{*}\right\|^{2} \\
\leq & \alpha_{n}\left\|u-x^{*}\right\|^{2}+\beta_{n}\left\|x_{n}-x^{*}\right\|^{2}+\left(1-\alpha_{n}-\beta_{n}\right)\left\|u_{n}-x^{*}\right\|^{2} \\
\leq & \alpha_{n}\left\|u-x^{*}\right\|^{2}+\beta_{n}\left\|x_{n}-x^{*}\right\|^{2}+\left(1-\alpha_{n}-\beta_{n}\right) \\
& \quad \times\left[\left\|x_{n}-x^{*}\right\|^{2}-\left\|x_{n}-u_{n}\right\|^{2}\right] \\
\leq & \alpha_{n}\left\|u-x^{*}\right\|^{2}+\left\|x_{n}-x^{*}\right\|^{2}-\left(1-\alpha_{n}-\beta_{n}\right)\left\|x_{n}-u_{n}\right\|^{2},
\end{aligned}
$$

that is,

$$
\begin{gathered}
\left(1-\alpha_{n}-\beta_{n}\right)\left\|x_{n}-u_{n}\right\|^{2} \leq \alpha_{n}\left\|u-x^{*}\right\|^{2}+\left\|x_{n}-x^{*}\right\|^{2}-\left\|x_{n+1}-x^{*}\right\|^{2} \\
\leq \alpha_{n}\left\|u-x^{*}\right\|^{2}+\left(\left\|x_{n}-x^{*}\right\|+\left\|x_{n+1}-x^{*}\right\|\right) \\
\times\left\|x_{n+1}-x_{n}\right\|,
\end{gathered}
$$

which implies that

$$
\lim _{n \rightarrow \infty}\left\|x_{n}-u_{n}\right\|=0
$$

We have

$$
\begin{aligned}
\left\|S y_{n}-y_{n}\right\| \leq & \left\|S y_{n}-S z_{n}\right\|+\left\|S z_{n}-x_{n}\right\|+\left\|x_{n}-u_{n}\right\|+\left\|u_{n}-y_{n}\right\| \\
\leq & \left\|y_{n}-z_{n}\right\|+\left\|S z_{n}-x_{n}\right\|+\left\|x_{n}-u_{n}\right\|+\left\|u_{n}-y_{n}\right\| \\
= & \left\|P_{C}\left(u_{n}-\lambda_{n} A u_{n}\right)-P_{C}\left(u_{n}-\lambda_{n} A y_{n}\right)\right\|+\left\|S z_{n}-x_{n}\right\| \\
& \quad+\left\|x_{n}-u_{n}\right\|+\left\|u_{n}-y_{n}\right\| \\
\leq & \lambda_{n}\left\|A u_{n}-A y_{n}\right\|+\left\|S z_{n}-x_{n}\right\|+\left\|x_{n}-u_{n}\right\|+\left\|u_{n}-y_{n}\right\| \\
\leq & \left(\lambda_{n} k+1\right)\left\|u_{n}-y_{n}\right\|+\left\|S z_{n}-x_{n}\right\|+\left\|x_{n}-u_{n}\right\| .
\end{aligned}
$$

This together with (3.8), (3.12), and (3.13) implies that

$$
\lim _{n \rightarrow \infty}\left\|S y_{n}-y_{n}\right\|=0
$$

Next we prove

$$
\limsup _{n \rightarrow \infty}\left\langle u-z_{0}, x_{n}-z_{0}\right\rangle \leq 0,
$$

where $z_{0}=P_{\mathrm{Fix}(S) \cap \mathrm{VI}(A, C) \cap \operatorname{EP}(F)}(u)$. First, we show that

$$
\limsup _{n \rightarrow \infty}\left\langle u-z_{0}, S y_{n}-z_{0}\right\rangle \leq 0
$$


To show this inequality, we can choose a subsequence $\left\{y_{n_{j}}\right\}$ of $\left\{y_{n}\right\}$ such that

$$
\lim _{j \rightarrow \infty}\left\langle u-x^{*}, S y_{n_{j}}-x^{*}\right\rangle=\limsup _{n \rightarrow \infty}\left\langle u-x^{*}, S y_{n}-x^{*}\right\rangle .
$$

Since $\left\{y_{n_{j}}\right\}$ is bounded, there exists a subsequence $\left\{y_{n_{j i}}\right\}$ of $\left\{y_{n_{j}}\right\}$ which converges weakly to $w$. Without loss of generality, we can assume that $y_{n_{j}} \rightarrow w$ weakly. From $\left\|S y_{n}-y_{n}\right\| \rightarrow 0$, we obtain $S y_{n_{j}} \rightarrow w$ weakly.

First we show $w \in \operatorname{EP}(F)$. By $u_{n}=T_{r_{n}} x_{n}$, we have

$$
F\left(u_{n}, y\right)+\frac{1}{r_{n}}\left\langle y-u_{n}, u_{n}-x_{n}\right\rangle \geq 0, \quad \forall y \in C .
$$

From the monotonicity of $F$, we have

$$
\frac{1}{r_{n}}\left\langle y-u_{n}, u_{n}-x_{n}\right\rangle \geq-F\left(u_{n}, y\right) \geq F\left(y, u_{n}\right)
$$

and hence

$$
\left\langle y-u_{n_{j}}, \frac{u_{n_{j}}-x_{n_{j}}}{r_{n_{j}}}\right\rangle \geq F\left(y, u_{n_{j}}\right) .
$$

Since $\frac{u_{n_{j}}-x_{n_{j}}}{r_{n_{j}}} \rightarrow 0$ and $u_{n_{j}} \rightarrow w$ weakly, from the lower semi-continuity of $F(x, y)$ on the second variable $y$, we have

$$
F(y, w) \leq 0
$$

for all $y \in C$. For $t$ with $0<t \leq 1$ and $y \in C$, let $y_{t}=t y+(1-t) w$. Since $y \in C$ and $w \in C$, we have $y_{t} \in C$ and hence $F\left(y_{t}, w\right) \leq 0$. So, from the convexity of the equilibrium bifunction $F(x, y)$ on the second variable $y$, we have

$$
\begin{aligned}
0 & =F\left(y_{t}, y_{t}\right) \\
& \leq t F\left(y_{t}, y\right)+(1-t) F\left(y_{t}, w\right) \\
& \leq t F\left(y_{t}, y\right)
\end{aligned}
$$

and hence $F\left(y_{t}, y\right) \geq 0$. Then we have

$$
F(w, y) \geq 0
$$

for all $y \in C$ and hence $w \in \operatorname{EP}(F)$.

Second, we show that $w \in \operatorname{VI}(A, C)$. Set

$$
B v= \begin{cases}A v+N_{C} v, & \text { if } v \in C, \\ \emptyset, & \text { if } v \notin C .\end{cases}
$$

Then $B$ is maximal monotone. Let $(v, u) \in G(B)$. Since $u-A v \in N_{C} v$ and $y_{n} \in C$, we have

$$
\left\langle v-y_{n}, u-A v\right\rangle \geq 0 .
$$


On the other hand, from $y_{n}=P_{C}\left(u_{n}-\lambda_{n} A u_{n}\right)$, we have

$$
\left\langle v-y_{n}, y_{n}-\left(u_{n}-\lambda_{n} A u_{n}\right)\right\rangle \geq 0
$$

and hence

$$
\left\langle v-y_{n}, \frac{y_{n}-u_{n}}{\lambda_{n}}+A u_{n}\right\rangle \geq 0
$$

It follows that

$$
\begin{aligned}
\left\langle v-y_{n_{i}}, u\right\rangle \geq & \left\langle v-y_{n_{i}}, A v\right\rangle \\
& -\left\langle v-y_{n_{i}}, \frac{y_{n_{i}}-u_{n_{i}}}{\lambda_{n_{i}}}+A u_{n_{i}}\right\rangle \\
= & \left\langle v-y_{n_{i}}, A v-\frac{y_{n_{i}}-u_{n_{i}}}{\lambda_{n_{i}}}-A u_{n_{i}}\right\rangle \\
= & \left\langle v-y_{n_{i}}, A v-A y_{n_{i}}\right\rangle+\left\langle v-y_{n_{i}}, A y_{n_{i}}-A u_{n_{i}}\right\rangle \\
& -\left\langle v-y_{n_{i}}, \frac{y_{n_{i}}-u_{n_{i}}}{\lambda_{n_{i}}}\right\rangle \\
\geq & \left\langle v-y_{n_{i}}, A y_{n_{i}}-A u_{n_{i}}\right\rangle-\left\langle v-y_{n_{i}}, \frac{y_{n_{i}}-u_{n_{i}}}{\lambda_{n_{i}}}\right\rangle,
\end{aligned}
$$

which implies that $\langle v-w, u\rangle \geq 0$. We have $w \in B^{-1}(0)$ and hence $w \in \operatorname{VI}(A, C)$.

Thirdly, we prove that $w \in \operatorname{Fix}(S)$. Assume that $w \notin \operatorname{Fix}(S)$. Since $y_{n_{j}} \rightarrow w$ and $w \neq S w$, by Opial's condition we have

$$
\begin{aligned}
\liminf _{j \rightarrow \infty}\left\|y_{n_{j}}-w\right\| & <\liminf _{j \rightarrow \infty}\left\|y_{n_{j}}-S w\right\| \\
& \leq \liminf _{j \rightarrow \infty}\left(\left\|y_{n_{j}}-S y_{n_{j}}\right\|+\left\|S y_{n_{j}}-S w\right\|\right) \\
& \leq \liminf _{j \rightarrow \infty}\left\|y_{n_{j}}-w\right\|,
\end{aligned}
$$

which is a contradiction. Then we get $w \in \operatorname{Fix}(S)$. Hence, we deduce that $w \in \operatorname{Fix}(S) \cap$ $\mathrm{VI}(A, C) \cap \mathrm{EP}(F)$. Therefore, from the property (iii) of $P_{C}$, we have

$$
\begin{aligned}
\limsup _{n \rightarrow \infty}\left\langle u-z_{0}, x_{n}-z_{0}\right\rangle & =\limsup _{n \rightarrow \infty}\left\langle u-z_{0}, S y_{n}-z_{0}\right\rangle \\
& =\lim _{j \rightarrow \infty}\left\langle u-z_{0}, S y_{n_{j}}-z_{0}\right\rangle \\
& =\left\langle u-z_{0}, w-z_{0}\right\rangle \leq 0 .
\end{aligned}
$$

Finally, we show $x_{n} \rightarrow z_{0}$, where $z_{0}=P_{\operatorname{Fix}(S) \cap V \mathrm{I}(A, C) \cap \mathrm{EP}(F)}(u)$.

From (3.1), we have

$$
\begin{aligned}
\left\|x_{n+1}-z_{0}\right\|^{2} & =\left\|\alpha_{n}\left(u-z_{0}\right)+\beta_{n}\left(x_{n}-z_{0}\right)+\left(1-\alpha_{n}-\beta_{n}\right)\left(S z_{n}-z_{0}\right)\right\|^{2} \\
& \leq\left\|\beta_{n}\left(x_{n}-z_{0}\right)+\left(1-\alpha_{n}-\beta_{n}\right)\left(S z_{n}-z_{0}\right)\right\|^{2}
\end{aligned}
$$




$$
\begin{aligned}
& +2 \alpha_{n}\left\langle u-z_{0}, x_{n+1}-z_{0}\right\rangle \\
\leq & {\left[\left(1-\alpha_{n}-\beta_{n}\right)\left\|S z_{n}-z_{0}\right\|+\beta_{n}\left\|x_{n}-z_{0}\right\|\right]^{2} } \\
& +2 \alpha_{n}\left\langle u-z_{0}, x_{n+1}-z_{0}\right\rangle \\
\leq & \left(1-\alpha_{n}\right)^{2}\left\|x_{n}-z_{0}\right\|+2 \alpha_{n}\left\langle u-z_{0}, x_{n+1}-z_{0}\right\rangle \\
\leq & \left(1-\alpha_{n}\right)\left\|x_{n}-z_{0}\right\|+2 \alpha_{n}\left\langle u-z_{0}, x_{n+1}-z_{0}\right\rangle .
\end{aligned}
$$

Hence, by Lemma 2.3, (3.14), and (3.15), we conclude that the sequence $x_{n}$ converges strongly to $z_{0}$. Since $\left\|y_{n}-x_{n}\right\| \rightarrow 0$ and $\left\|u_{n}-x_{n}\right\|$, we have $y_{n} \rightarrow z_{0}$ and $u_{n} \rightarrow z_{0}$. This completes the proof.

\section{Applications}

Taking $\beta_{n} \equiv 0$ for all $n \geq 0$ in (3.1), we immediately obtain the following result.

Theorem 4.1 Let $C$ be a nonempty closed convex subset of a real Hilbert space H. Let $F$ be a bifunction from $C \times C \rightarrow \mathbf{R}$ satisfying $(\mathrm{H} 1)-(\mathrm{H} 4)$. Let $A$ be a monotone and $k$-Lipschitz continuous mapping of $C$ into $H$, and let $S$ be a nonexpansive mapping of $C$ into itself such that $\operatorname{Fix}(S) \cap \operatorname{VI}(A, C) \cap \operatorname{EP}(F) \neq \emptyset$. Let $\left\{\alpha_{n}\right\}$ be a sequence in $(0,1)$, and let $\left\{\lambda_{n}\right\}$ and $\left\{r_{n}\right\}$ be two sequences in $(0, \infty)$. For fixed $u \in C$ and given $x_{0} \in C$ arbitrarily, let the sequences $\left\{x_{n}\right\},\left\{y_{n}\right\}$, and $\left\{u_{n}\right\}$ be generated iteratively by

$$
\left\{\begin{array}{l}
F\left(u_{n}, y\right)+\frac{1}{r_{n}}\left\langle y-u_{n}, u_{n}-x_{n}\right\rangle \geq 0, \quad \forall y \in C, \\
y_{n}=P_{C}\left(u_{n}-\lambda_{n} A u_{n}\right), \\
x_{n+1}=\alpha_{n} u+\left(1-\alpha_{n}-\beta_{n}\right) S P_{C}\left(u_{n}-\lambda_{n} A y_{n}\right) .
\end{array}\right.
$$

Suppose the following conditions are satisfied:

(a) $\left\{\lambda_{n} k\right\} \subset(0,1-\delta)$ for some $\delta \in(0,1)$;

(b) $\lim _{n \rightarrow \infty} \alpha_{n}=0$ and $\sum_{n=0}^{\infty} \alpha_{n}=\infty$.

Then the sequences $\left\{x_{n}\right\},\left\{y_{n}\right\}$, and $\left\{u_{n}\right\}$ generated by (4.1) converge strongly to $P_{\mathrm{Fix}(S) \cap \mathrm{VI}(A, C) \cap \mathrm{EP}(F)}(u)$ if and only if $\lim _{n \rightarrow \infty}\left\|x_{n+1}-x_{n}\right\|=0$.

In (3.1), we put $F(x, y)=0$ for all $x, y \in C$ and $r_{n}=1$ for all $n \in N$. Then we have $u_{n}=$ $P_{C} x_{n}=x_{n}$. Then we obtain the following theorem.

Theorem 4.2 Let $C$ be a nonempty closed convex subset of a real Hilbert space H. Let $A$ be a monotone and $k$-Lipschitz continuous mapping of $C$ into $H$, and let $S$ be a nonexpansive mapping of $C$ into itself such that $\operatorname{Fix}(S) \cap \operatorname{VI}(A, C) \neq \emptyset$. Let $\left\{\alpha_{n}\right\}$ and $\left\{\beta_{n}\right\}$ be two sequences in $(0,1)$, and let $\left\{\lambda_{n}\right\}$ be a sequence in $(0, \infty)$. For fixed $u \in C$ and given $x_{0} \in C$ arbitrarily, let the sequences $\left\{x_{n}\right\}$ and $\left\{y_{n}\right\}$ be generated iteratively by

$$
\left\{\begin{array}{l}
y_{n}=P_{C}\left(x_{n}-\lambda_{n} A x_{n}\right), \\
x_{n+1}=\alpha_{n} u+\beta_{n} x_{n}+\left(1-\alpha_{n}-\beta_{n}\right) S P_{C}\left(x_{n}-\lambda_{n} A y_{n}\right) .
\end{array}\right.
$$

Suppose the following conditions are satisfied:

(a) $\left\{\lambda_{n} k\right\} \subset(0,1-\delta)$ for some $\delta \in(0,1)$;

(b) $\lim _{n \rightarrow \infty} \alpha_{n}=0$ and $\sum_{n=0}^{\infty} \alpha_{n}=\infty$;

(c) $\lim \sup _{n \rightarrow \infty} \beta_{n}<1$. 
Then the sequences $\left\{x_{n}\right\}$ and $\left\{y_{n}\right\}$ generated by (4.2) converge strongly to $P_{\mathrm{Fix}(S) \cap \mathrm{VI}(A, C)}(u)$ if and only if $\lim _{n \rightarrow \infty}\left\|x_{n+1}-x_{n}\right\|=0$.

In (4.2), we put $\beta_{n} \equiv 0$ for all $n \geq 0$. Then we obtain the following result.

Theorem 4.3 Let $C$ be a nonempty closed convex subset of a real Hilbert space H. Let $A$ be a monotone and $k$-Lipschitz continuous mapping of $C$ into $H$, and let $S$ be a nonexpansive mapping of $C$ into itself such that $\operatorname{Fix}(S) \cap \operatorname{VI}(A, C) \neq \emptyset$. Let $\left\{\alpha_{n}\right\}$ be a sequence in $(0,1)$, and let $\left\{\lambda_{n}\right\}$ be a sequence in $(0, \infty)$. For fixed $u \in C$ and given $x_{0} \in C$ arbitrarily, let the sequences $\left\{x_{n}\right\}$ and $\left\{y_{n}\right\}$ be generated iteratively by

$$
\left\{\begin{array}{l}
y_{n}=P_{C}\left(x_{n}-\lambda_{n} A x_{n}\right), \\
x_{n+1}=\alpha_{n} u+\left(1-\alpha_{n}-\beta_{n}\right) S P_{C}\left(x_{n}-\lambda_{n} A y_{n}\right) .
\end{array}\right.
$$

Suppose the following conditions are satisfied:

(a) $\left\{\lambda_{n} k\right\} \subset(0,1-\delta)$ for some $\delta \in(0,1)$;

(b) $\lim _{n \rightarrow \infty} \alpha_{n}=0$ and $\sum_{n=0}^{\infty} \alpha_{n}=\infty$.

Then the sequences $\left\{x_{n}\right\}$ and $\left\{y_{n}\right\}$ generated by (4.3) converge strongly to $P_{\mathrm{Fix}(S) \cap \mathrm{II}(A, C)}(u)$ if and only if $\lim _{n \rightarrow \infty}\left\|x_{n+1}-x_{n}\right\|=0$.

Remark 4.4 It is clear that Theorem 4.3 indicates the result in Zeng and Yao [11].

A mapping $T: C \rightarrow C$ is called strictly pseudocontractive if there exists $k$ with $0 \leq k<1$ such that

$$
\|T x-T y\|^{2} \leq\|x-y\|^{2}+k\|(I-T) x-(I-T) y\|^{2}
$$

for all $x, y \in C$. Put $A=I-T$, then we have

$$
\|(I-A) x-(I-A) y\|^{2} \leq\|x-y\|^{2}+k\|A x-A y\|^{2} .
$$

On the other hand,

$$
\|(I-A) x-(I-A) y\|^{2}=\|x-y\|^{2}+\|A x-A y\|^{2}-2\langle x-y, A x-A y\rangle .
$$

Hence we have

$$
\langle x-y, A x-A y\rangle \geq \frac{1-k}{2}\|A x-A y\|^{2} \geq 0 .
$$

This shows that if $T$ is a strictly pseudocontractive mapping; then $I-T$ is a monotone and $\frac{2}{1-k}$-Lipschitz continuous mapping. Note that $\operatorname{Fix}(T)=\mathrm{VI}(I-T, C)$. Hence it is easy to obtain the following theorems.

Theorem 4.5 Let $C$ be a nonempty closed convex subset of a real Hilbert space H. Let $F$ be a bifunction from $C \times C \rightarrow \mathbf{R}$ satisfying $(\mathrm{H} 1)-(\mathrm{H} 4)$. Let $T$ be a $k$-strictly pseudocontractive mapping of $C$ into $H$, and let $S$ be a nonexpansive mapping of $C$ into itself such that $\operatorname{Fix}(S) \cap$ $\operatorname{Fix}(T) \cap \operatorname{EP}(F) \neq \emptyset$. Let $\left\{\alpha_{n}\right\}$ and $\left\{\beta_{n}\right\}$ be two sequences in $(0,1)$, and let $\left\{\lambda_{n}\right\}$ and $\left\{r_{n}\right\}$ be 
two sequences in $(0, \infty)$. For fixed $u \in C$ and given $x_{0} \in C$ arbitrarily, let the sequences $\left\{x_{n}\right\}$, $\left\{y_{n}\right\}$, and $\left\{u_{n}\right\}$ be generated iteratively by

$$
\left\{\begin{array}{l}
F\left(u_{n}, y\right)+\frac{1}{r_{n}}\left\langle y-u_{n}, u_{n}-x_{n}\right\rangle \geq 0, \quad \forall y \in C, \\
y_{n}=P_{C}\left(u_{n}-\lambda_{n}(I-T) u_{n}\right), \\
x_{n+1}=\alpha_{n} u+\beta_{n} x_{n}+\left(1-\alpha_{n}-\beta_{n}\right) S P_{C}\left(u_{n}-\lambda_{n}(I-T) y_{n}\right) .
\end{array}\right.
$$

Suppose the following conditions are satisfied:

(a) $\left\{\lambda_{n} k\right\} \subset(0,1-\delta)$ for some $\delta \in(0,1)$;

(b) $\lim _{n \rightarrow \infty} \alpha_{n}=0$ and $\sum_{n=0}^{\infty} \alpha_{n}=\infty$;

(c) $\lim _{\sup } \sin _{n \rightarrow \infty} \beta_{n}<1$.

Then the sequences $\left\{x_{n}\right\},\left\{y_{n}\right\}$, and $\left\{u_{n}\right\}$ generated by (4.4) converge strongly to $P_{\mathrm{Fix}(S) \cap \mathrm{Fix}(T) \cap \mathrm{EP}(F)}(u)$ if and only if $\lim _{n \rightarrow \infty}\left\|x_{n+1}-x_{n}\right\|=0$.

Theorem 4.6 Let C be a nonempty closed convex subset of a real Hilbert space H. Let $T$ be a $k$-strictly pseudocontractive mapping of $C$ into $H$, and let $S$ be a nonexpansive mapping of $C$ into itself such that $\operatorname{Fix}(S) \cap \operatorname{Fix}(T) \neq \emptyset$. Let $\left\{\alpha_{n}\right\}$ and $\left\{\beta_{n}\right\}$ be two sequences in $(0,1)$, and let $\left\{\lambda_{n}\right\}$ and $\left\{r_{n}\right\}$ be two sequences in $(0, \infty)$. For fixed $u \in C$ and given $x_{0} \in C$ arbitrarily, let the sequences $\left\{x_{n}\right\}$ and $\left\{y_{n}\right\}$ be generated iteratively by

$$
\left\{\begin{array}{l}
y_{n}=P_{C}\left(x_{n}-\lambda_{n}(I-T) x_{n}\right), \\
x_{n+1}=\alpha_{n} u+\beta_{n} x_{n}+\left(1-\alpha_{n}-\beta_{n}\right) S P_{C}\left(x_{n}-\lambda_{n}(I-T) y_{n}\right) .
\end{array}\right.
$$

Suppose the following conditions are satisfied:

(a) $\left\{\lambda_{n} k\right\} \subset(0,1-\delta)$ for some $\delta \in(0,1)$;

(b) $\lim _{n \rightarrow \infty} \alpha_{n}=0$ and $\sum_{n=0}^{\infty} \alpha_{n}=\infty$;

(c) $\limsup _{n \rightarrow \infty} \beta_{n}<1$.

Then the sequences $\left\{x_{n}\right\}$ and $\left\{y_{n}\right\}$ generated by (4.5) converge strongly to $P_{\mathrm{Fix}(S) \cap \mathrm{Fix}(T)}(u)$ if and only if $\lim _{n \rightarrow \infty}\left\|x_{n+1}-x_{n}\right\|=0$.

Competing interests

The authors declare that they have no competing interests.

\section{Authors' contributions}

All authors read and approved the final manuscript.

\section{Author details}

${ }^{1}$ School of Information Engineering, Nanjing Xiaozhuang University, Nanjing, 211171, China. ${ }^{2}$ Department of Information Management, Cheng Shiu University, Kaohsiung, 833, Taiwan. ${ }^{3}$ Center for General Education, Kaohsiung Medical University, Kaohsiung, 807, Taiwan. ${ }^{4}$ School of Mathematics and Information Science, Beifang University of Nationalities, Yinchuan, 750021, China.

\section{Acknowledgements}

Yeong-Cheng Liou was supported in part by NSC 101-2628-E-230-001-MY3 and NSC 103-2923-E-037-001-MY3. Li-Jun Zhu was supported in part by NNSF of China (61362033). This research is supported partially by Kaohsiung Medical University Aim for the Top Universities Grant, Grant No. KMU-TP103F00.

\section{Received: 13 February 2015 Accepted: 29 May 2015 Published online: 17 June 2015}

\section{References}

1. Blum, E, Oettli, W: From optimization and variational inequalities to equilibrium problems. Math. Stud. 63, 123-145 (1994)

2. Noor, MA, Oettli, W: On general nonlinear complementarity problems and quasi equilibria. Matematiche 49, 313-331 (1994)

3. Noor, MA, Noor, Kl: On equilibrium problems. Appl. Math. E-Notes 4, 125-132 (2004) 
4. Noor, MA: Fundamentals of equilibrium problems. Math. Inequal. Appl. 9, 529-566 (2006)

5. Combettes, PL, Hirstoaga, SA: Equilibrium programming in Hilbert spaces. J. Nonlinear Convex Anal. 6, 117-136 (2005)

6. Nadezhkina, N, Takahashi, W: Weak convergence theorem by an extragradient method for nonexpansive mappings and monotone mappings. J. Optim. Theory Appl. 128, 191-201 (2006)

7. Yao, Y, Noor, MA, Liou, YC: On iterative methods for equilibrium problems. Nonlinear Anal. 70, 497-507 (2009)

8. Combettes, PL, Hirstoaga, SA: Equilibrium programming using proximal-like algorithms. Math. Program. 78, 29-41 (1997)

9. Takahashi, S, Takahashi, W: Viscosity approximation methods for equilibrium problems and fixed point problems in Hilbert spaces. J. Math. Anal. Appl. 331, 506-515 (2007)

10. Yao, Y, Noor, MA, Zainab, S, Liou, YC: Mixed equilibrium problems and optimization problems. J. Math. Anal. Appl. 352, 319-329 (2009)

11. Zeng, LC, Yao, JC: Strong convergence theorem by an extragradient method for fixed point problems and variational inequality problems. Taiwan. J. Math. 10, 1293-1303 (2006)

12. Plubtieng, S, Punpaeng, R: A general iterative method for equilibrium problems and fixed point problems in Hilbert spaces. J. Math. Anal. Appl. 336, 455-469 (2007)

13. Yao, Y, Liou, YC, Yao, JC: Convergence theorem for equilibrium problems and fixed point problems of infinite family of nonexpansive mappings. Fixed Point Theory Appl. 2007, Article ID 64363 (2007)

14. Yao, Y, Liou, YC, Lee, C, Wong, MM: Convergence theorem for equilibrium problems and fixed point problems. Fixed Point Theory 10, 347-363 (2009)

15. Marino, G, Colao, V, Muglia, L, Yao, Y: Krasnoselski-Mann iteration for hierarchical fixed points and equilibrium problem. Bull. Aust. Math. Soc. 79, 187-200 (2009)

16. Yao, Y, Cho, YJ, Liou, YC, Agarwal, RP: Constructed nets with perturbations for equilibrium and fixed point problems J. Inequal. Appl. 2014, 334 (2014)

17. Browder, FE, Petryshyn, WV: Construction of fixed points of nonlinear mappings in Hilbert spaces. J. Math. Anal. Appl. 20, 197-228 (1967)

18. Liu, F, Nashed, MZ: Regularization of nonlinear ill-posed variational inequalities and convergence rates. Set-Valued Anal. 6, 313-344 (1998)

19. Stampacchia, G: Formes bilinéaires coercitives sur les ensembles convexes. C. R. Acad. Sci. Paris 258, 4413-4416 (1964)

20. Yao, JC: Variational inequalities with generalized monotone operators. Math. Oper. Res. 19, $691-705$ (1994)

21. Zeng, LC: On a general projection algorithm for variational inequalities. J. Optim. Theory Appl. 97, 229-235 (1998)

22. Chadli, O, Schaible, S, Yao, JC: Regularized equilibrium problems with an application to noncoercive hemivariational inequalities. J. Optim. Theory Appl. 121, 571-596 (2004)

23. Yao, Y, Liou, YC, Yao, JC: An extragradient method for fixed point problems and variational inequality problems. J. Inequal. Appl. 2007, Article ID 38752 (2007)

24. Yao, Y, Agarwal, RP, Liou, YC: Iterative algorithms for quasi-variational inclusions and fixed point problems of pseudocontractions. Fixed Point Theory Appl. 2014, 82 (2014)

25. Yao, Y, Agarwal, RP, Postolache, M, Liou, YC: Algorithms with strong convergence for the split common solution of the feasibility problem and fixed point problem. Fixed Point Theory Appl. 2014, 183 (2014)

26. Takahashi, W, Toyoda, M: Weak convergence theorems for nonexpansive mappings and monotone mappings. J. Optim. Theory Appl. 118, 417-428 (2003)

27. Korpelevich, GM: An extragradient method for finding saddle points and for other problems. Èkon. Mat. Metody 12, 747-756 (1976)

28. Xu, HK: Viscosity approximation methods for nonexpansive mappings. J. Math. Anal. Appl. 298, $279-291$ (2004)

\section{Submit your manuscript to a SpringerOpen ${ }^{\circ}$ journal and benefit from:}

- Convenient online submission

Rigorous peer review

- Immediate publication on acceptance

- Open access: articles freely available online

- High visibility within the field

- Retaining the copyright to your article 